Artigo

\title{
Utilização de Modelos de Mesoescala como Ferramenta Inicial para o Mapeamento Eólico do Estado da Paraíba
}

\author{
Soetânia Santos de Oliveira ${ }^{1}$ iD , Enio Pereira de Souza ${ }^{1}$ \\ ${ }^{1}$ Departamento de Ciências Atmosféricas, Universidade Federal de Campina Grande, \\ Campina Grande, PB, Brasil.
}

Recebido em 12 de Dezembro de 2017 - Aceito em 4 de Maio de 2018

\begin{abstract}
Resumo
A utilização de modelos numéricos para avaliação dos recursos eólicos vem crescendo cada vez mais. Diante disso, foi realizada uma avaliação do desempenho dos modelos BRAMS e WRF como ferramentas na investigação inicial de sites eólicos no estado da Paraíba. As simulações para um período de três anos sugerem que as regiões centrais do estado tendem a apresentar ventos mais intensos que as demais regiões e que a primavera é a estação que apresenta ventos de maior intensidade. Foram gerados também cenários para março e setembro, meses que estão, respectivamente, entre os de menor e maior intensidade de vento no estado. Para esses cenários o Bias variou de -0,31 a -2,24 m/s e o EQM de 0,88 a 2,40 m/s para o BRAMS. Para o WRF o Bias foi de 0,53 a $1,81 \mathrm{~m} / \mathrm{s}$ e EQM de 0,79 a 1,92 m/s. Os menores Bias e EQM foram obtidos para as localidades analisadas na Borborema nos meses de março (BRAMS) e no Agreste em setembro (WRF). Estes resultados sugerem que os modelos precisam ser melhor configurados para uma maior representatividade do vento local, especialmente com relação às parametrizações da camada limite e da superfície. De modo geral, os resultados revelam a coerência dos modelos em termos de intensificação/desintensificação dos ventos de acordo com as características sazonais da área de estudo.
\end{abstract}

Palavras-chave: potencial eólico, modelos de mesoescala.

\section{Utilization of Mesoscale Models as Initial Tool for Wind Mapping of the Paraíba State}

\begin{abstract}
The use of numerical models as a tool for evaluating wind resources has increased in recent years. In this study, an evaluation of the performance of the models BRAMS and WRF was carried out as an initial step on the investigation of wind sites in the state of Paraiba-Brazil. Simulations over a three-year period suggest that the more intense winds are located at the central regions of the state and that they tend to be higher in the spring, in comparison with the other seasons. Scenarios were also generated for March and September, that are, respectively, among the months of lowest and highest wind intensity in the state. For those scenarios the Bias ranged from -0.31 to $-2.24 \mathrm{~m} / \mathrm{s}$ and the MSE from 0.88 to $2.40 \mathrm{~m} / \mathrm{s}$ for BRAMS. For WRF, the Bias was 0.53 to $1.81 \mathrm{~m} / \mathrm{s}$ and $M S E$ was 0.79 to $1.92 \mathrm{~m} / \mathrm{s}$. The lowest Bias and MSE were obtained for the locations analyzed in Borborema for March (BRAMS) and in the Agreste for September (WRF). Those results suggest that the models need further calibration for better simulating the local wind, especially with respect to boundary layer and surface parameterizations. In general, the results show the coherence of the models in terms of intensification/weakening of the winds according to the seasonal characteristics of the study area.
\end{abstract}

Keywords: wind power, mesoescale models.

\section{Introdução}

A diversificação das fontes e as novas tecnologias usadas para produção de energia elétrica tem sido tema amplamente discutido em vários segmentos do meio aca- dêmico. Em termos de segurança energética é importante descentralizar a produção de energia por meio de recursos hídricos, tendo em vista a vulnerabilidade destes às condições climáticas (Silva et al., 2005). A energia eólica vem se

Autor de correspondência: Soetânia Santos de Oliveira, soetania@gmail.com. 
destacando ao longo dos tempos e tem se mostrado uma ótima alternativa para produção de energia elétrica.

De acordo com o Boletim de Energia Eólica: Brasil e Mundo - Base 2016, do Ministério de Minas e Energia MME, o Brasil foi o quinto colocado no ranking mundial de expansão de potência eólica, com 2,5 GW em 2016 (MME, 2017). Ainda segundo o boletim, para 2026, a previsão do Plano Decenal de Energia - PDE2026, é que a capacidade instalada eólica chegue a $25,8 \mathrm{GW}$ (inclusive geração distribuída), respondendo por $12,5 \%$ do total. A região Nordeste deverá ficar com $90 \%$ da capacidade eólica total.

No cenário nacional o crescimento do potencial eólico tem significativa predominância na região Nordeste do Brasil - NEB. Dos 495 empreendimentos eólicos em funcionamento no país até julho de 2017 , cerca de $80 \%$ estão localizados no NEB (ANEEL, 2017).

A definição do potencial eólico de uma região tem na velocidade média do vento local um elemento central, uma vez que este é diretamente proporcional ao cubo da velocidade do vento (Santos et al., 2015; Sansigolo, 2005). Isto evidencia a necessidade de uma análise prévia do lugar, para que se tenha tanto um melhor aproveitamento da potencialidade do vento, como a definição da viabilidade técnica e econômica do empreendimento (Oliveira e Souza, 2017; Silva et al., 2003).

A dinâmica atmosférica no NEB é influenciada, direta ou indiretamente, por vários fenômenos meteorológicos. Dentre os quais, estão o posicionamento da Zona de Convergência Intertropical - ZCIT, que influência de maneira direta a direção e intensidade dos ventos alísios, os Vórtices Ciclônicos de Altos Níveis - VCANs, os Distúrbios Ondulatórios de Leste - DOLs, as anomalias na temperatura do Oceano Pacífico e a passagem de Sistemas Frontais /Frentes Frias (Pinto et al., 2014; Silva et al., 2011; Kayano e Andreoli, 2009). Há ainda os mecanismos de brisas marítimas no litoral e de vale-montanha no continente, que contribuem fortemente para o aumento na intensidade e na variação da direção dos ventos alísios (Oliveira, 2013; Valença, 2010; Silva, 2003).

Diferentes metodologias vêm sendo utilizadas para avaliar o comportamento do vento e assim fornecer informações que possam auxiliar o setor eletro-energético, dentre elas o uso de métodos estatísticos (Wang et al., 2018; Ko et al., 2015; Chang, 2011) e de modelos computacionais (Oliveira e Souza, 2017; Mathew e Mariappan, 2014; Lazic, 2010). O interesse em aplicações da modelagem numérica da atmosfera para a estimativa do potencial eólico é crescente e já movimenta um mercado significativo. $\mathrm{O}$ uso de modelos numéricos pode auxiliar tanto na identificação de localidades com elevado potencial eólico quanto no uso operacional em integrações diárias, na previsão de geração de energia em curto prazo (Oliveira e Souza, 2017).

A utilização de modelos numéricos para avaliação dos recursos eólicos tem despertado o interesse de vários pesquisadores. Estudos como os realizados por Lima et al.
(2012), Ramos et al. (2013), Pinto et al. (2014), Oliveira e Souza (2017) e Mariano et al. (2017), buscaram avaliar o desempenho dos modelos em reproduzir dados de ventos para áreas do NEB. Em todos estes estudos, o desempenho dos modelos foi avaliado por meio da comparação, a partir de análise estatística, entre o vento simulado e o observado, evidenciando uma boa relação entre dados analisados.

No entanto, a velocidade e a direção do vento são variáveis difíceis de serem simuladas com precisão, em virtude da sua grande variabilidade no espaço e no tempo, devido à situação geográfica do local, a rugosidade da superfície, o relevo e a variabilidade intra-anual da vegetação (Vendramini, 1986).

Nesse contexto, e diante da expansão de interesses relacionados à utilização da energia eólica, frente à necessidade de suprir a demanda energética e minimizar o elevado custo para identificar localidades com características adequadas à exploração desse recurso, o objetivo deste estudo foi investigar o desempenho de modelos de mesoescala na prospecção do vento para o aproveitamento eólico na Paraíba, um dos estados brasileiros que ainda não dispõem de um atlas eólico. Para isso os modelos BRAMS - Brazilian Developments on the Regional Atmospheric Modelling System, e WRF - Weather Research and Forecasting System, foram utilizados para gerar cenários de condições de vento e assim analisar o comportamento sazonal (BRAMS) e os períodos de maior e menor intensidade do vento (BRAMS e WRF).

O fato do estado não dispor de um atlas eólico acaba dificultando a exploração de áreas com alto potencial eólico. Saber como o vento se comporta a curto/longo prazo é muito importante quando se quer aproveitar esse recurso para geração de energia. Portanto, espera-se que os resultados desse estudo contribuam para a compreensão e utilização de modelos numéricos como ferramentas na investigação inicial sites eólicos, servindo como um direcionador para instalação de torres de medição anemométrica.

\section{Metodologia}

\section{1. Área de estudo}

O estado da Paraíba está situado no extremo leste do NEB, entre os paralelos $6^{\circ} \mathrm{S}-8^{\circ} \mathrm{S}$ e os meridianos $34^{\circ} \mathrm{W}-38^{\circ} \mathrm{W}$, e é a área de estudo desse trabalho. Incluído totalmente na zona tropical, o estado apresenta clima quente com médias de temperatura que variam de $22^{\circ} \mathrm{C}$ a $30^{\circ} \mathrm{C}$ e índices pluviométricos relativamente elevados no litoral e baixo no interior. A Paraíba ocupa $0,66 \%$ da área territorial brasileira, destacando-se por apresentar condições de vento favoráveis à produção de energia eólica (Oliveira, 2013; Mariano Neto, 2003; Rodriguez, 2002). Na Fig. 1 é mostrada a localização da Paraíba e suas mesorregiões.

Segundo Sauer et al. (2006), o Brasil oferece excelentes sítios para instalação de parques eólicos, sendo que as melhores áreas se encontram ao longo da costa e nas 


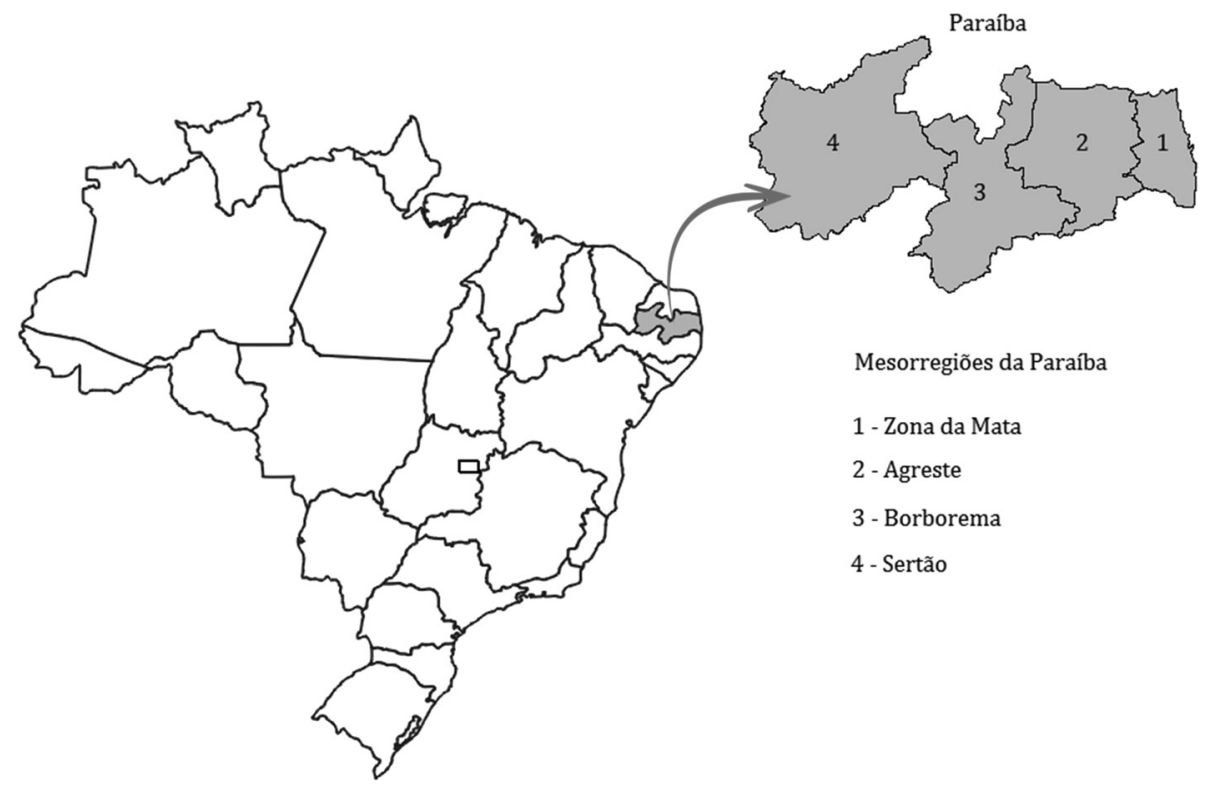

Figura 1 - Localização do estado da Paraíba e suas mesorregiões (Adaptado de Oliveira e Souza, 2017).

áreas altas do interior do país. Nesse contexto, a Paraíba é privilegiada por sua localização geográfica, pois está em uma área sob a influência dos ventos alísios, que são praticamente constantes em direção e velocidade, e pela topografia que favorece sua distribuição espacial.

\subsection{Modelos numéricos utilizados}

Dois modelos numéricos de mesoescala foram utilizados neste trabalho: o BRAMS na versão 4.2 e o WRF na versão 3.4. O BRAMS é um modelo atmosférico baseado nas equações não hidrostáticas compressíveis (Negri et al., 2015; Longo et al., 2013; Freitas et al., 2009) que simula circulações que vão desde a micro até a macro escala, sendo frequentemente aplicado à simulações de mesoescala (Silva, 2016). O BRAMS foi desenvolvido a partir do modelo RAMS, que tem sua estrutura básica descrita por Pielke et al. (1992).

Além dos vários recursos e modificações incluídos para melhorar a representação numérica de processos físi$\cos$, fundamentais em regiões tropicais e subtropicais (Freitas et al., 2005, 2009; 2016), o BRAMS conta com estadoda-arte em parametrizações físicas de transferência radiativa, difusão turbulenta na camada limite planetária e microfísica de nuvens, dentre outros (Negri et al., 2015). Isto tudo amplia as funcionalidades originais do RAMS para um modelo ambiental totalmente integrado.

O WRF é um modelo atmosférico, não hidrostático, projetado tanto para previsão numérica de tempo e clima, como para pesquisa. Este modelo é produto da parceria entre vários órgãos americanos, dentre eles o National Oceanic and Atmospheric Administration's - NOAA e o National Center for Atmospheric Research - NCAR. Considerado o estado-da-arte em modelos numéricos (Skamarock. et al., 2008; Wang et al., 2011; Carvalho et al.,
2012), o WRF têm seus conceitos físicos baseados na conservação de massa, explicitando as variações de energia, momentum e umidade do ar (Ramos et al., 2013). A descrição sobre a arquitetura e desempenho do WRF pode ser encontrada em Skamarock et al. (2008). Segundo Powers et al. (2017), desde o seu lançamento em 2000, o WRF tornou-se o modelo atmosférico mais usado no mundo, além de ter se tornado um verdadeiro modelo comunitário, impulsionado pelos desenvolvimentos e contribuições de uma base de usuários mundialmente ativa.

\subsection{Descrição dos experimentos}

Os modelos foram integrados com duas grades aninhadas (Fig. 2). A grade externa, com 16 km de resolução horizontal, abrange parte do Nordeste e do oceano Atlântico e a grade interna, com resolução de $4 \mathrm{~km}$, compreende toda a Paraíba.

Inicialmente, a fim de ajustar os modelos para as condições locais, foram realizados testes com conjuntos de parametrizações diferentes. No entanto, os melhores resultados foram obtidos com os esquemas listados na Tabela 1 e demais configurações apresentadas a seguir. Ainda assim, a confiabilidade das estimativas pode apresentar diferenças significativas em função das parametrizações e parâmetros físicos utilizados (Pinto et al., 2014).

As parametrizações foram ativadas tanto para a grade interna como para a externa, exceto nos experimentos realizados com o WRF, onde se verificou melhores resultados quando a parametrização de cúmulos foi desativada para a grade interna em virtude da formação excessiva de nuvens convectivas. As condições iniciais para ambos os modelos foram os dados de reanálise do NCEP/NCAR de $2,5^{\circ}$ de resolução. Quanto aos níveis verticais, os modelos foram 


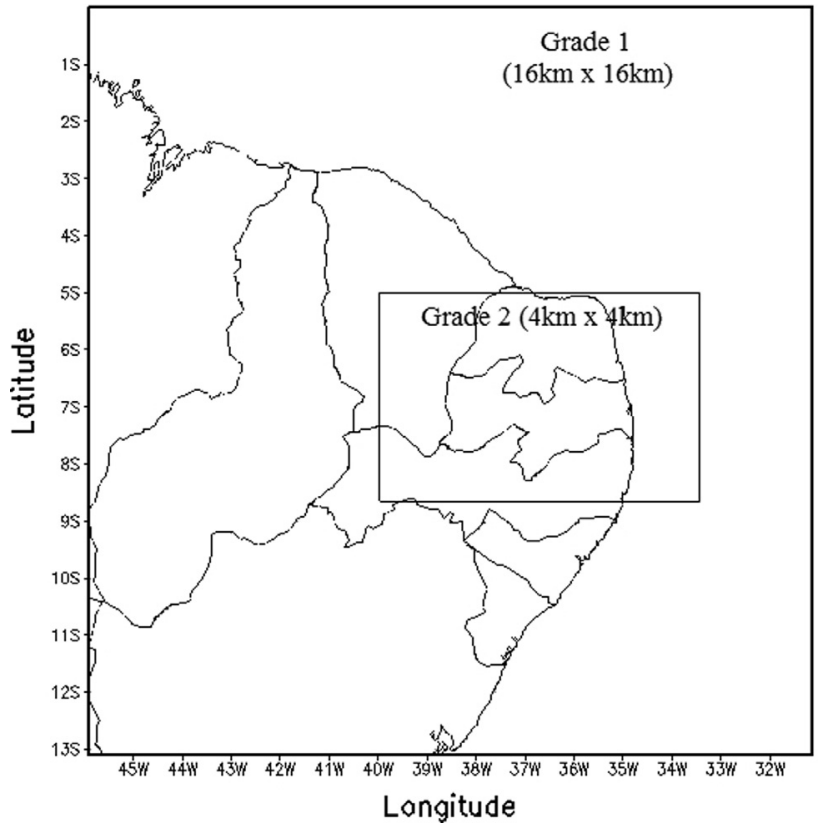

Figura 2 - Representação das grades horizontais utilizadas nos modelos.

integrados com 42 e 38 níveis, para o BRAMS e o WRF, respectivamente, com tempo de relaxamento de $6 \mathrm{~h}$.

Os esquemas propostos por Mellor e Yamada (1982) e YSU (Hong et al., 2006) para a Camada Limite Planetária definido nos modelos BRAMS e WRF, respectivamente, estão entre os mais usados para simulações de vento. $\mathrm{O}$ esquema de Mellor e Yamada (1982) é um esquema de fechamento de turbulência de $1,5^{\mathrm{a}}$ ordem de nível 2 , baseado na equação prognóstica da energia cinética turbulenta ECT, com mistura vertical local. Já o esquema YSU é um esquema não-local de primeira ordem com uma camada de entranhamento explícita e um perfil K (coeficiente de difusão turbulenta) parabólico em uma camada de mistura instável.

Com o intuito de fazer uma análise sazonal do potencial eólico da Paraíba visando auxiliar no planejamento energético da região, o modelo BRAMS foi integrado com duas grades aninhadas para as quatro estações do ano entre 2007 e 2009. Foram produzidas saídas a cada meia-hora, de modo que as médias são calculadas com base em quase 1500 valores/mês para cada ponto.

Em um segundo momento, os modelos BRAMS e WRF foram integrados para os meses de março e setembro de 2010. As simulações começaram a 00 UTC do dia $1^{\circ}$ de cada mês. Neste caso, foram produzidas saídas a cada hora, de modo que as médias são calculadas com base em mais de 700 valores/mês para cada ponto e as discussões são relacionadas aos resultados provenientes da grade interna.

As análises, tanto para as quatro estações do ano como para os meses de março e setembro de 2010, foram realizadas a partir de dados extraídos a altura de $70 \mathrm{~m}$, que corresponde a um dos níveis típicos de medições anemométricas para estudos eólicos por estar próximo dos hubs dos aerogeradores. Tanto para a sazonalidade como para março e setembro, será mostrado o mapa médio para todo o estado.

Os meses de março e setembro de 2010, bem como a altura para análise, foram escolhidos por uma questão de disponibilidade de dados. Além disso, de acordo com dados coletados em estações meteorológicas (convencionais e automáticas) do INMET instaladas na Paraíba, esses meses encontram-se entre os que apresentam menor e maior intensidade do vento ao longo do estado.

A ocorrência de fenômenos meteorológicos distintos durante esses meses influenciam diretamente a intensidade do vento na Paraíba. De acordo com a Climanálise (2010a) durante o mês de março de 2010 foi observada a atuação de VCANs sobre o NEB na maioria das pêntadas de março. O posicionamento deste sistema próximo ou sobre o continente, como ocorre na $6^{a}$ pêntada, pode causar um enfraquecimento dos ventos de superfície na área de estudo.

Ainda segundo a Climanálise (2010b), em setembro de 2010 a ZCIT atuou aproximadamente entre $5^{\circ} \mathrm{Ne}$ $10^{\circ} \mathrm{N}$, oscilando em torno de sua posição climatológica para o referido mês. Observou-se também a atuação mais intensa do sistema de alta pressão do Atlântico Sul, conhecido como Alta Subtropical do Atlântico Sul ASAS. Essa configuração faz com que haja uma intensificação dos ventos de sudeste/leste, que chegam ao litoral nordestino.

Tabela 1 - Esquemas de parametrizações utilizados nos experimentos.

\begin{tabular}{|c|c|c|}
\hline \multirow[t]{2}{*}{ Parametrizações } & \multicolumn{2}{|l|}{ Modelo } \\
\hline & BRAMS & WRF \\
\hline Microfísica & Walko et al. (1995) & Lin et al. (1983) \\
\hline Convecção de cúmulos & Cov. Rasa: Souza (1999); Conv. Profunda: Grell - Dévényi (2002) & Grell-Dévényi ensemble (2002) \\
\hline Radiação de onda curta & Chen e Cotton (1983) & RRTMG (Mlawer et al., 1997) \\
\hline Radiação de onda longa & Chen e Cotton (1983) & RRTMG (Mlawer et al., 1997) \\
\hline Camada limite planetária & Mellor e Yamada (1982) & YSU (Hong et al., 2006) \\
\hline
\end{tabular}

Fonte: Oliveira e Souza (2017). 


\section{4. Índices estatísticos}

Segundo Oliveira (2013) uma das maneiras utilizadas para avaliar o desempenho dos modelos numéricos é a comparação das estimativas por eles fornecidas com os dados observados. De acordo com os estudos desenvolvidos por Weber et al. (1982), De Maria (2007), Cunha et al. (2008) entre outros a melhor forma de avaliar um modelo numérico é utilizando um conjunto de índices estatísticos, de forma que possam ser minimizados os erros de interpretação (Lima, 2011). Portanto, nesse estudo serão utilizadas as seguintes métricas estatísticas: o Bias, o Erro Absoluto Médio (EA), O Erro Quadrático Médio $(E Q M)$ e o Índice de Correlação $(r)$.

O Bias é calculado a partir de:

$$
\text { Bias }=\frac{1}{N} \sum_{i=1}^{n}\left(\phi_{i}-\phi_{0}\right)
$$

O Erro Absoluto Médio ( $E A)$ é dado por:

$$
E A=\frac{1}{N} \sum_{i=1}^{n}\left|\phi_{i}-\phi_{0}\right|
$$

O Erro Quadrático Médio (EQM) é obtido a partir de:

$$
E Q M=\left[\frac{1}{N} \sum_{i=1}^{n}\left(\phi_{i}-\phi_{0}\right)\right]^{\frac{1}{2}}
$$

O coeficiente de correlação estatística ou coeficiente de correlação de Pearson $(r)$ é dado por:

$$
r=\frac{\sum\left(\phi_{i}-\bar{\phi}_{i}\right) \cdot\left(\phi_{0}-\bar{\phi}_{0}\right)}{\sqrt{\left[\sum\left(\phi_{i}-\bar{\phi}_{i}\right)^{2}\right] \cdot\left[\sum\left(\phi_{0}-\bar{\phi}_{0}\right)^{2}\right]}}
$$

em que $N$ é o número de dados, $\phi_{i}$ e $\phi_{0}$ correspondem, respectivamente, aos valores simulados e observados.

De acordo com Devore (2006) essa correlação pode variar de muito fraca a muito forte de acordo com os intervalos de $r$ contidos na Tabela 2.

Os dados simulados por ambos os modelos foram comparados a dados coletados a partir de torres anemométricas, padronizadas para estudos de exploração eólica. Os dados simulados foram extraídos em pontos correspondentes à localização das torres anemométricas, que por questão de confidencialidade de dados não podem ter suas coordenadas geográficas reveladas. Para efeito didático elas serão referenciadas com o nome da mesorregião onde
Tabela 2 - Coeficiente de correlação estatística ou coeficiente de correlação de Pearson.

\begin{tabular}{ll}
\hline Intervalos & Definição \\
\hline 0,00 a 0,19 & Correlação bem fraca \\
0,20 a 0,39 & Correlação fraca \\
0,40 a 0,69 & Correlação moderada \\
0,70 a 0,89 & Correlação forte \\
0,90 a 1,00 & Correlação bem forte \\
\hline
\end{tabular}

Fonte: Devore (2006).

se encontram instaladas, sendo doravante chamadas Torre Agreste, Torre Borborema e Torre Sertão, cujas características dos locais de instalação estão dispostas na Tabela 3.

É importante ressaltar que para o cálculo destes índices foram considerados apenas períodos onde os dados fossem pareados, ou seja, quando não houvesse ocorrência de problemas relacionados à ausência e/ou falhas nos dados.

\section{Resultados}

\subsection{Sazonalidade}

A topografia do estado juntamente com o vento predominante (quadrante leste-sudeste), explicam a maior porção da distribuição de vento observada. A Fig. 3 mostra o mapa de elevação da área de estudo.

As mudanças no comportamento da circulação geral da atmosfera ao longo do ano causam variações sazonais significativas na velocidade e na direção predominante do vento (Silva, 2003). Nesse estudo, apenas a variação na velocidade do vento foi analisada, sendo tal análise realizada para as mesorregiões do estado: Zona da Mata, Agreste, Borborema e Sertão (Fig. 1).

Nas Figs. 4a e 4b têm-se a média da velocidade dos ventos a $70 \mathrm{~m}$ de altura, entre os anos 2007-2009, geradas a partir do modelo BRAMS para o verão e o outono, respectivamente. Nota-se que ao longo do estado a magnitude da velocidade do vento apresenta-se semelhante para ambas estações.

Analisando as mesorregiões separadamente percebe-se que na Zona da Mata, próximo a região litorânea, a velocidade média do vento simulado é da ordem de $4 \mathrm{~m} / \mathrm{s}$

\begin{tabular}{|c|c|c|c|c|c|}
\hline Torres anemométricas & Altitude (m) & Terreno & Vegetação & Temperatura média $\left({ }^{\circ} \mathrm{C}\right)$ & $\begin{array}{l}\text { Precipitação média } \\
\text { anual }(\mathrm{mm})\end{array}$ \\
\hline Torre Agreste & 500 & Pequena depressão & Caatinga & 25 & 750 \\
\hline Torre Borborema & 500 & Plano & Caatinga & 26 & 512 \\
\hline Torre Sertão & 800 & Montanhoso & Caatinga & 28 & 736 \\
\hline
\end{tabular}
tanto para o verão quanto para o outono. À medida que o vento penetra o continente esses valores vão diminuindo.

Tabela 3 - Características geográficas e climatológicas do local das torres anemométricas.

Fonte: Oliveira e Souza (2017). 


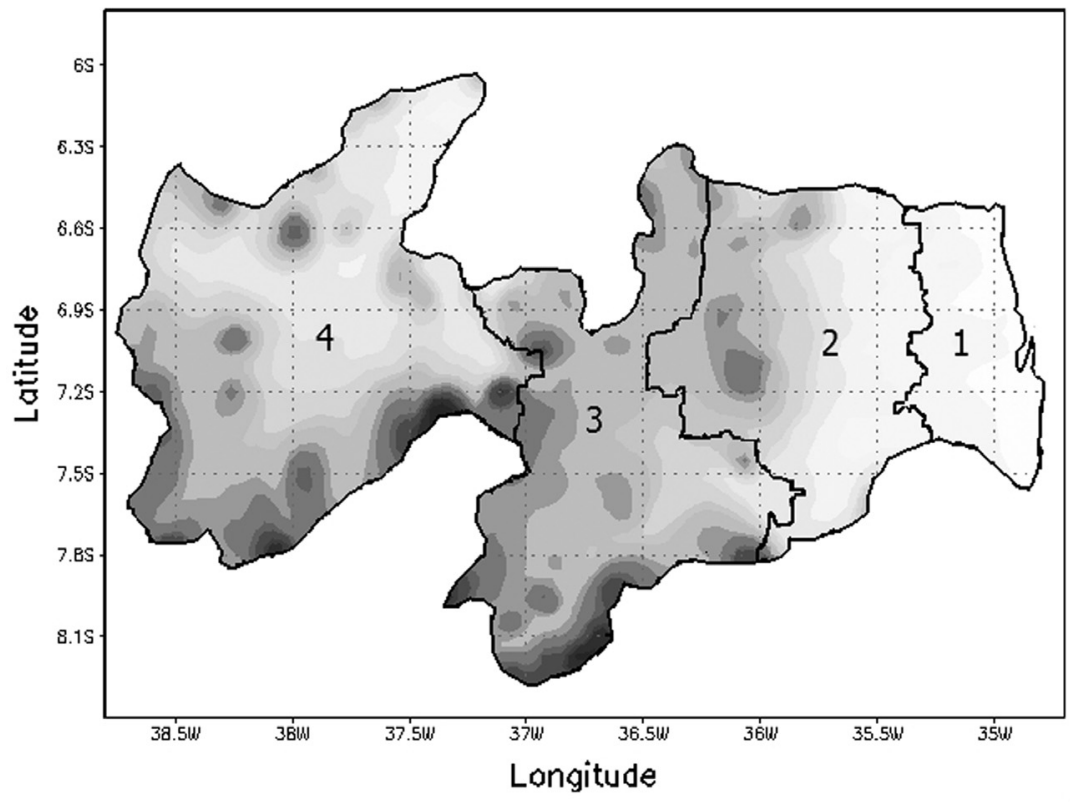

$\begin{array}{llllllllllllll}50 & 150 & 200 & 300 & 350 & 450 & 500 & 600 & 650 & 750 & 800 & 900 & 950 & 1050\end{array}$

(m)

Figura 3 - Mapa de elevação (m) da Paraíba com resolução de 4 km.

a)
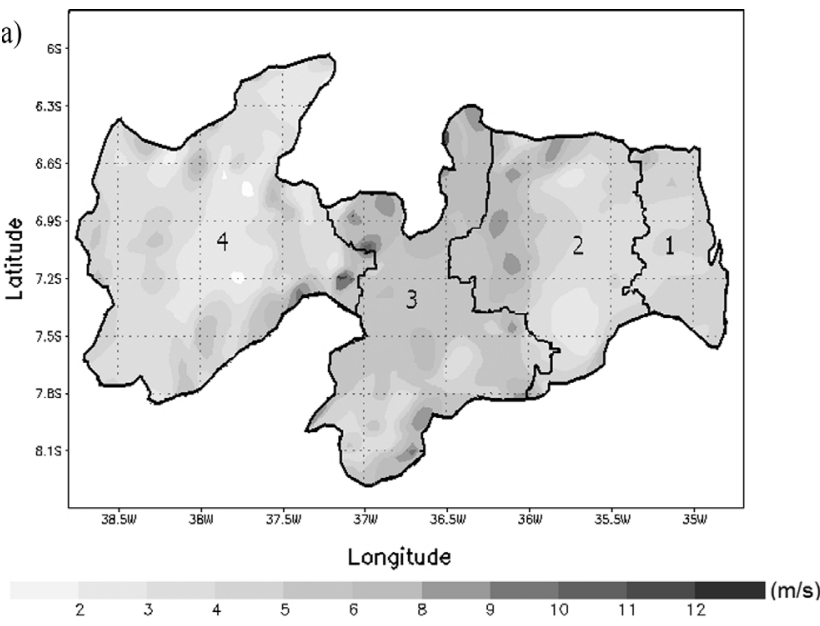

c)
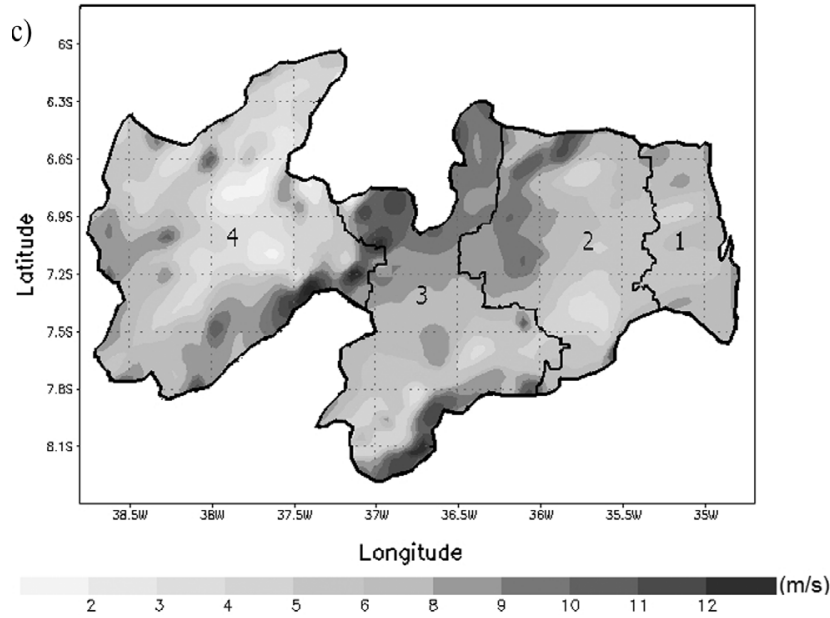
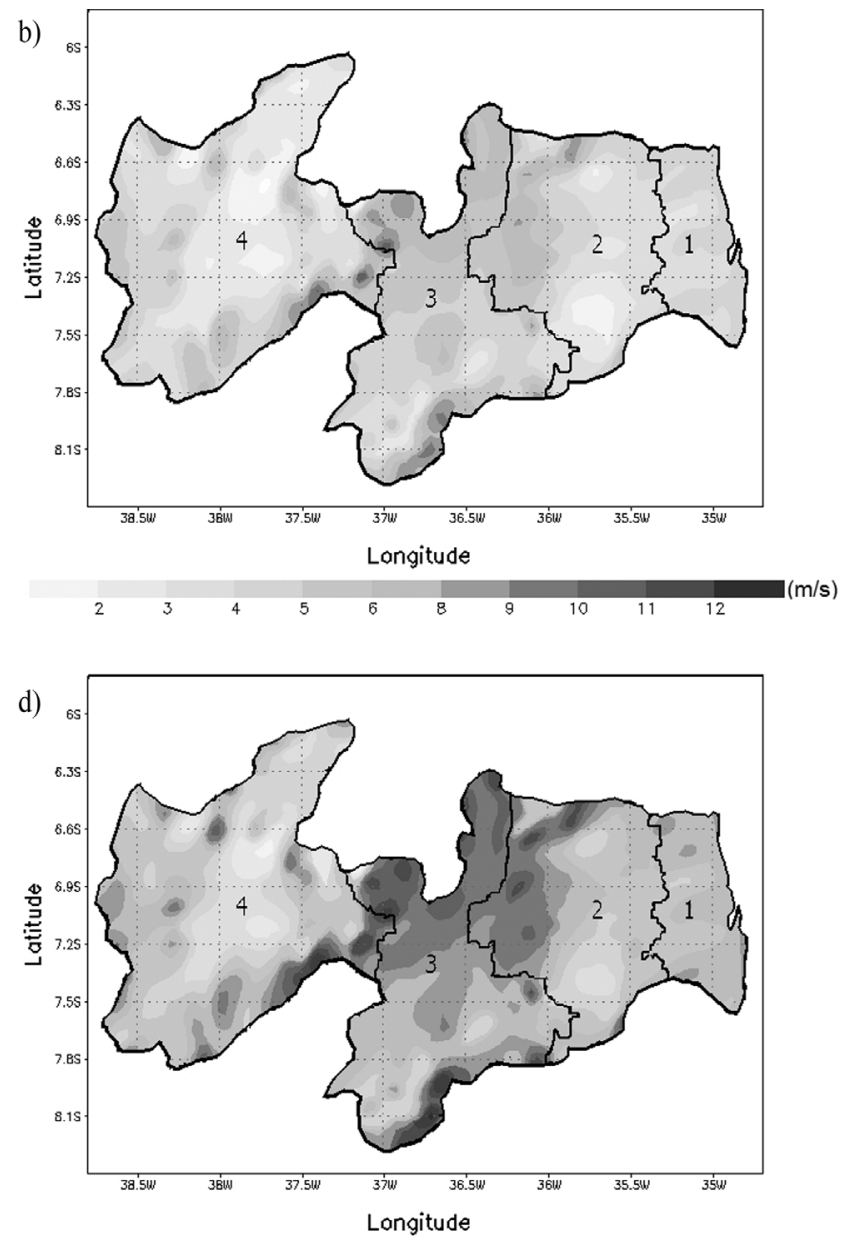

Longitude

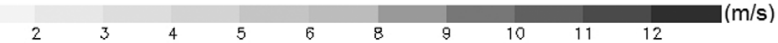

Figura 4 - Velocidade média do vento (m/s) para o período de 2007-2009 a 70 m de altura para: (a) Verão, (b) Outono, (c) Inverno e (d) Primavera. 
Isso ocorre, muito provavelmente, devido ao efeito da rugosidade imposta pelo terreno. A rugosidade do terreno exerce forte influencia na variação da velocidade do vento com a altura. Um terreno plano com vegetação rasteira (baixa rugosidade) tem uma variação de vento com a altura bem menor do que um terreno irregular (alta rugosidade) como áreas urbanas, por exemplo (Custódio, 2007).

No caso do Agreste, seguindo na direção de leste para oeste, observam-se núcleos de intensidade relativamente baixa para ambas estações. Em seguida o vento com baixa velocidade é impulsionado e aumenta de intensidade. Acredita-se que isso ocorra devido a uma possível relação com o relevo altamente acidentado da região, o que poderia causar desde jatos de baixos níveis a brisas vale-montanha, além da canalização dos ventos.

A Borborema é a região onde o vento apresenta-se mais intenso, com velocidade média predominante entre $5 \mathrm{e}$ $6 \mathrm{~m} / \mathrm{s}$ para o verão e de 4 a $6 \mathrm{~m} / \mathrm{s}$ para o outono. No entanto, é possível observar áreas específicas ao norte e ao sul em que a velocidade média chega a $8 \mathrm{~m} / \mathrm{s}$ no verão e $9 \mathrm{~m} / \mathrm{s}$ no outono.

Quanto ao Sertão, tanto no verão quanto no outono, verificam-se áreas de baixa magnitude da velocidade do vento, em que predominam velocidades que variam de 2 a $4 \mathrm{~m} / \mathrm{s}$. Observa-se ainda locais com magnitude mais elevada, particularmente na porção leste-sudeste da região, área esta cuja altitude supera os $700 \mathrm{~m}$.

As médias das velocidades do vento para o inverno e a primavera podem ser visualizadas, respectivamente, nas Figs. $4 \mathrm{c}$ e $4 \mathrm{~d}$. Nota-se que a partir do inverno as velocidades do vento tendem a aumentar razoavelmente.

$\mathrm{Na}$ Zona da Mata, tanto para o inverno quanto para a primavera, percebe-se que a faixa litorânea apresenta valores de velocidade média em torno de $7 \mathrm{~m} / \mathrm{s}$. Esses valores diminuem gradativamente à medida que o vento se afasta do litoral.

No Agreste, como um todo, percebe-se que a velocidade varia de 3 a $10 \mathrm{~m} / \mathrm{s}$. No entanto, as áreas onde se encontram as maiores magnitudes estão concentradas na parte norte e oeste desta região. Comparando-se as Figs. 4c e $4 \mathrm{~d}$, verifica-se que do inverno para primavera houve uma expansão das áreas cuja magnitude do vento está acima de $8 \mathrm{~m} / \mathrm{s}$, em particular na porção oeste da região.

As médias na região da Borborema variam de 4 a $12 \mathrm{~m} / \mathrm{s}$ em ambas estações, sendo as maiores intensidades observadas na parte norte e em uma pequena área ao sul. Percebe-se ainda, que na primavera houve uma expansão das áreas com magnitude do vento superior a $7 \mathrm{~m} / \mathrm{s}$ em relação àquelas verificadas no inverno. A maior intensidade do vento durante a primavera está relacionada ao posicionamento e à intensidade da Alta Subtropical de Atlântico Sul (Rao et al., 1993) e à ausência de processos convectivos. A existência de precipitação convectiva, tanto observada quanto modelada, tende a estabeler uma característica mais turbulenta ao vento próximo à superfície, o que diminui o potencial é́lico da região no primeiro semestre.

No Sertão, as áreas de destaque com velocidades acima de $8 \mathrm{~m} / \mathrm{s}$ em ambas estações, encontram-se entre o leste e o sudeste dessa região. Na parte central do Sertão, região em que a altitude varia de 200 a 450 m, estão as áreas com as menores velocidades, algo entre 2 e $5 \mathrm{~m} / \mathrm{s}$. É provável que isso ocorra devido a essa região estar a sotavendo de regiões bem mais elevadas. Já no oeste, no sul e em pequenas áreas do extremo norte, predominam velocidades superiores a $5 \mathrm{~m} / \mathrm{s}$. Isso é verificado tanto no inverno quanto na primavera.

De modo geral, tem-se que os menores valores da velocidade média do vento nas quatro estações foram obtidos na região central do Sertão. Percebe-se também que as maiores intensidades são verificadas no interior do estado, principalmente na porção norte das regiões da Borborema e do Agreste. Tais fatos podem ser atribuidos, dentre outro fatores que influenciam o comportamento do vento, ao efeito da topografia da região.

Segundo Layton (2009), para tornar a energia eólica viável em uma determinada área são necessárias velocidades do vento de $3,0 \mathrm{~m} / \mathrm{s}$ para turbinas pequenas e de $6,0 \mathrm{~m} / \mathrm{s}$ para grandes turbinas. Abaixo desses valores o conteúdo energético do vento não justifica o seu aproveitamento (Rüncos et al., 2005). Portanto, com base nos valores médios simulados para as quatro estações, a Paraíba teoricamente dispõe de condições de vento favoráveis para geração de energia eólica, principalmente na parte norte da Borborema e oeste do Agreste.

Apesar de apenas 3 dos 15 parques eólicos em funcionamento na Paraíba estarem localizados na região da Borborema (ANEEL, 2018), investidores vêm demonstrando grande interesse no potencial eólico do interior do estado. No Leilão de Geração A-6, realizado pela Agência Nacional de Energia Elétrica - Aneel, em dezembro de 2017, foi comercializada a energia de nove parques eólicos na Paraíba, localizados nos municípios de Santa Luzia, São Mamede, São José do Sabugi e Areias de Baraúnas (FEB, 2017). Estes municípios estão na área entre $6,7^{\circ} \mathrm{S}-7,2^{\circ} \mathrm{S}$ e $36,7^{\circ} \mathrm{W}-37,2^{\circ} \mathrm{W}$, onde o modelo aponta a existência de áreas favoráveis à produção eólica, o que sugere a eficácia deste em indicar tais áreas.

\subsection{Cenários}

\subsubsection{Março de 2010}

As Figs. 5a e 5b apresentam os valores médios da velocidade do vento a $70 \mathrm{~m}$ de altura obtidos, respectivamente, com os modelos BRAMS e WRF. Comparando os resultados, nota-se que a magnitude do vento é simulada com maior intensidade pelo WRF (Fig. 5b). Essa diferença pode estar relacionada à parametrização da camada limite adotada. De acordo com Shin e Hong (2011), Hu et al. (2012, 2013) e Floors et al. (2013), por exemplo, algumas versões do WRF com o esquema YSU, dentre elas a versão 

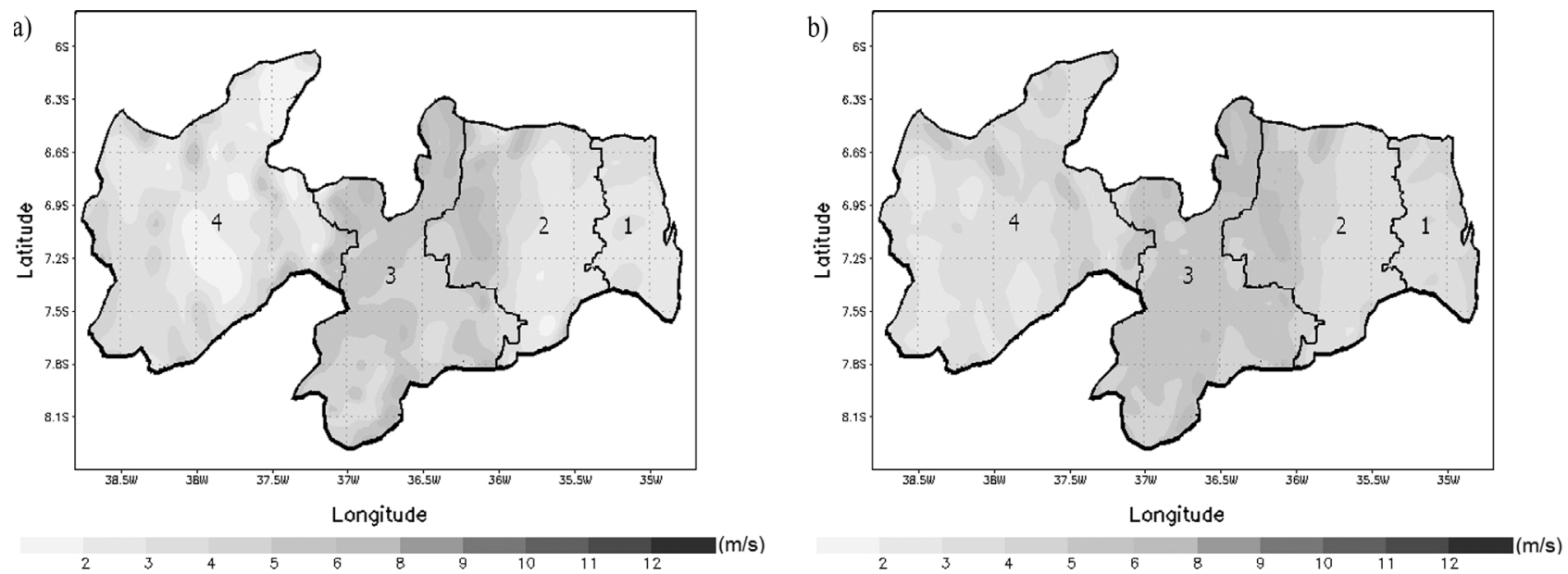

Figura 5 - Velocidade média do vento em 70 m para março de 2010: (a) BRAMS e (b) WRF.

3.4 utilizada neste estudo, tende a superestimar o vento durante a noite. Sendo isso atribuído a um bug de codificação no esquema YSU implementado nas versões iniciais do WRF. A descrição e correção deste bug podem ser encontradas em Jiménez et al. (2012).

Em uma análise mais detalhada, percebe-se que no cenário simulado pelo BRAMS na Zona da Mata, as velocidades estão entre 2 e $3 \mathrm{~m} / \mathrm{s}$, com áreas de $3 \mathrm{~m} / \mathrm{s}$ ao norte, na parte central e ao sul da região. Já o WRF simula uma magnitude predominante de $3 \mathrm{~m} / \mathrm{s}$, com uma faixa de $4 \mathrm{~m} / \mathrm{s}$ na faixa litorânea da região.

No Agreste, verifica-se que para ambos os modelos há uma intensificação na magnitude da velocidade do vento no sentido leste-oeste e que ambos apontam as mesmas áreas de maior magnitude.

Os resultados dos modelos sugerem que a Borborema é a região com maior intensidade de vento no estado, com velocidade média predominante de $5 \mathrm{~m} / \mathrm{s}$ em quase toda a região e núcleos de $6 \mathrm{~m} / \mathrm{s}$ em várias partes, especialmente ao norte. Para o BRAMS há uma área de menor intensidade na parte leste, entre $7,2^{\circ} \mathrm{S}-7,8^{\circ} \mathrm{S}$ e $36,5^{\circ} \mathrm{W}-36^{\circ} \mathrm{W}$, com um núcleo de $3 \mathrm{~m} / \mathrm{s}$, entre $7,5^{\circ} \mathrm{S}-7,8^{\circ} \mathrm{S}$, que não foram simulados pelo WRF. Essa região está localizada em uma área na qual há uma diferença de cerca de $100 \mathrm{~m}$ de altitude em relação à vizinhança, o que pode ter causado a diferença entre os resultados simulados, pois mesmo com ambos os modelos utilizando os mesmos arquivos de topografia o BRAMS pode ter simulado melhor os efeitos físicos daquela região.

No Sertão, o BRAMS simula núcleos mais intensos que o WRF em pontos específicos, como ,por exemplo, na parte leste da região. Em contrapartida, são observadas áreas de vento mais intenso a norte de $6,3^{\circ} \mathrm{S}$, observadas apenas no cenário gerado pelo WRF. Esta região apresenta um pequeno conjunto de montanhas e talvez por este motivo o WRF tenha intensificado o vento nesta área. Nos locais onde esses núcleos coincidem para ambos os modelos, o WRF gerou áreas maiores.
De modo geral, sobre todo o estado a magnitude da velocidade manteve-se relativamente baixa, com valor máximo de $6 \mathrm{~m} / \mathrm{s}$ observado principalmente ao norte da Borborema, para ambos os modelos. A atuação de VCANs próximo à área de estudo, na maioria das pêntadas de março, associado a efeitos de mesoescala, como as variações térmicas ao longo do estado, podem ter influenciado de forma negativa na intensificação dos ventos, sugerindo a coerência dos resultados simulados pelos modelos.

\subsubsection{Setembro 2010}

Ao contrário do observado para março no cenário gerado com o BRAMS (Fig. 6a), em setembro é visualizada próximo à costa do estado uma faixa de velocidade de $7 \mathrm{~m} / \mathrm{s}$ que acompanha quase todo o entorno litorâneo. Para o WRF (Fig. 6b) essa faixa de velocidade é um pouco mais pronunciada sendo visualizada ao longo de toda área litorânea. Verifica-se ainda na Zona da Mata, para o cenário do BRAMS, duas áreas com baixa magnitude na parte central da região, enquanto o WRF gerou um cenário mais homogêneo com magnitude predominante de $6 \mathrm{~m} / \mathrm{s}$. Tal fato pode ter ocorrido devido ao BRAMS conseguir simular melhor a distribuição do vento na região.

No caso do Agreste, ambos os modelos geraram núcleos de velocidade máxima em torno dos $10 \mathrm{~m} / \mathrm{s}$, sendo que para o BRAMS estes núcleos ocupam áreas maiores. Nota-se também que o BRAMS apresenta uma área de baixa magnitude entre $7,2^{\circ} \mathrm{S}-7,5^{\circ} \mathrm{S}$. O WRF também apresenta esta área, porém com velocidade de $1 \mathrm{~m} / \mathrm{s}$ maior que o BRAMS. É possível que esses resultados tenham sido causados por uma tendência presente nos dados de reanálise.

Quanto a Borborema, verifica-se que a variação entre máxima e mínima velocidade do vento é da ordem de $7 \mathrm{~m} / \mathrm{s}$ para o BRAMS e de $6 \mathrm{~m} / \mathrm{s}$ para o WRF. Nos dois cenários há áreas de máxima ao sul, ao norte e a noroeste da região. Nesta última o WRF simula ventos mais intensos. Semelhante ao cenário para o mês de março, aqui também é 

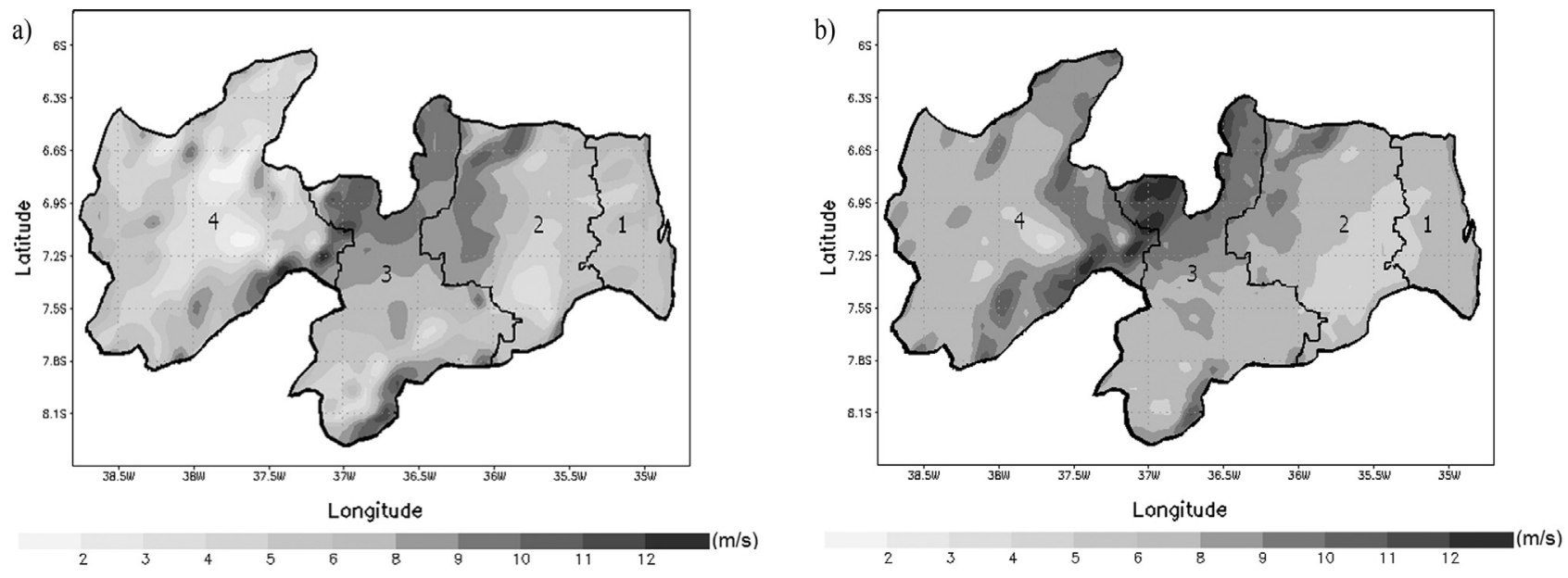

Figura 6 - Velocidade média do vento em 70 m para setembro de 2010: (a) BRAMS e (b) WRF.

possível ver entre $7,5^{\circ} \mathrm{S}-7,8^{\circ} \mathrm{S}$ e $35,5^{\circ} \mathrm{W}-36^{\circ} \mathrm{W}$ uma área de baixa magnitude identificada apenas no cenário gerado pelo BRAMS.

No Sertão enquanto as velocidades dos ventos produzidos pelo BRAMS variam de 2 a $12 \mathrm{~m} / \mathrm{s}$, para o WRF essa variação é de 4 a $12 \mathrm{~m} / \mathrm{s}$. Em termos quantitativos, assim como para a Borborema, a maior diferença entre os modelos está na velocidade mínima simulada. Uma grande área de baixa magnitude é observada no caso do BRAMS, sendo esta bem menor no cenário do WRF. Outra grande divergência entre os modelos está na parte norte, onde há uma diferença de $4 \mathrm{~m} / \mathrm{s}$ entre os valores predominantes simulados.

No geral, verificam-se nos cenários gerados pelo modelo BRAMS maiores amplitudes do vento, enquanto o WRF apresenta-se mais homogêneo. Segundo Silva et al. (2012), tal fato pode estar relacionado com as parametrizações de camada limite, de radiação (Marchi, 2011), e/ou de convecção que interferem diretamente nos fluxos turbulentos e de calor em baixos níveis da atmosfera (Silva, 2009). No que diz respeito à altura, os dois modelos são teoricamente condizentes com a intensificação do vento com a altura, a exemplo da região central da Paraíba. De acordo com Burton et al. (2001), em geral, há uma aceleração do fluxo de vento em regiões de topografia mais elevada, como na região centro-norte do estado, por exemplo. Da mesma forma, a topografia pode produzir áreas onde a velocidade do vento é reduzida, como acontece em regiões de vales ou onde os padrões de fluxo resultam em pontos de estagnação.

Considerando o fato de que a ZCIT encontrava-se em sua posição mais ao norte nessa época, entre $5^{\circ} \mathrm{N} \mathrm{e} 10^{\circ} \mathrm{N}$ (Climanálise, 2010b), e que isso, associado à atuação mais intensa da ASAS, influencia de forma positiva a intensificação dos alísios de sudeste nessa época, é fácil verificar a coerência nos resultados dos modelos quanto a essa intensificação. Note-se que os valores máximos simulados para esse mês $(\sim 12 \mathrm{~m} / \mathrm{s})$, correspondem ao dobro daqueles encontrados para o mês de março.

A julgar-se pelo interesse de grandes empresas do ramo de energia eólica na parte central do estado, onde os modelos apontaram áreas favoráveis à produção eólica, em ambos os cenários simulados, pode-se reafirmar sua eficácia em indicar inicialmente regiões de grande potencial eólico. De acordo com Sá (2016), a implementação de complexos eólicos nessas áreas já está prevista para os próximos anos. Além disso, as áreas apontadas pelos modelos coincidem com as indicadas no Atlas do Potencial Eólico Brasileiro (Amarante et al., 2001). Portanto, os modelos podem servir como um direcionamento inicial para a instalação de torres de medições anemométricas para exploração eólica.

\subsection{3. Índices estatísticos}

Os índices estatísticos são mostrados na Tabela 4. Tais parâmetros foram obtidos a partir de séries de dados observados e simulados para os meses analisados.

Analisando os resultados do Bias, nota-se que tanto o BRAMS como o WRF subestimaram as velocidades do vento para as três localidades analisadas no mês de março, exceto o WRF, que superestimou o vento em $0,53 \mathrm{~m} / \mathrm{s}$ para localidade da Torre Borborema. Para o mês de setembro os modelos superestimaram os valores observados. A exceção neste caso é a subestimativa do WRF $(-0,33 \mathrm{~m} / \mathrm{s})$ para a localidade da Torre Agreste. Nota-se também que as maiores e menores diferenças foram encontradas para os dados simulados com o BRAMS para o mês de março, sendo o maior Bias de $-2,24 \mathrm{~m} / \mathrm{s}$ para o local da Torre Agreste e o menor de $-0,31 \mathrm{~m} / \mathrm{s}$ para o local da Torre Borborema.

Estes resultados sugerem que tanto os fenômenos meteorológicos como os parâmetros físicos das áreas analisadas (orografia, rugosidade, brisas marítima-terrestre e vale-montanha, etc.), que interferem na caracterização do vento local, podem não estar sendo muito bem representados pelos modelos devido à configuração utilizada neste 
estudo. Além disso, as condições iniciais também podem não ser representativas para a região, uma vez que pode haver escassez de dados de superfície, radiossondas, etc, para serem assimilados.

De modo geral, a superestimativa/subestimativa do vento pelos modelos deve-se, provavelmente, a problemas relacionados à utilização de parametrizações inadequada, associadas às condições de contorno adotadas. Portanto, recomenda-se a realização de novos experimentos para se investigar a eficácia de outras parametrizações na simulação dos processos físicos que influenciam a velocidade do vento no estado.

Com relação ao $E A$, verifica-se que os valores variaram de $0,65-2,26 \mathrm{~m} / \mathrm{s}$ para as velocidades simuladas com o BRAMS e de $0,65-1,81 \mathrm{~m} / \mathrm{s}$ com o WRF, sendo os menores $E A$ obtidos, com ambos os modelos, para a localidade da Torre Borborema no mês de março e para a localidade da Torre Agreste em setembro.

Quanto à dispersão geral dos dados simulados, interpretada por meio do $E Q M$, os valores obtidos ficaram entre $0,88-2,40 \mathrm{~m} / \mathrm{s}$ para o BRAMS e entre $0,79-1,92 \mathrm{~m} / \mathrm{s}$ para o WRF. Assim como no caso dos EA, os menores EQM foram obtidos para as localidades das Torres Borborema e Agreste nos meses de março e setembro, respectivamente. Nos demais casos, os valores do EQM foram superiores a $1,22 \mathrm{~m} / \mathrm{s}$.

Em estudos semelhantes para localidades da região NEB, como o desenvolvido por Ramos et al. (2013) utilizando o WRF para previsão do vento, os valores de $E Q M$ variaram de $2,36-3,83 \mathrm{~m} / \mathrm{s}$ e Bias de $-0,04$ a $2,28 \mathrm{~m} / \mathrm{s}$. Também para o NEB, Gonçalves (2011), fazendo uso do modelo ETA para prognóstico do vento, encontrou valores de $E Q M$ entre 2,30-4,63 m/s e Bias de $-0,43$ a $3,64 \mathrm{~m} / \mathrm{s}$. A diferença entre estes resultados e os obtidos para Paraíba, pode estar no fato das regiões analisadas apresentarem condições climatológicas e geográficas diferentes, apesar de todas estarem situadas no NEB.

Em termos de correlação os coeficientes obtidos mostram que, de acordo com a classificação de Devore (2006), há forte correlação entre os dados simulados e observados $(r>0,7)$, salvo no caso do WRF para a Torre Borborema em março, cujo coeficiente de correlação indica uma correlação moderada $(0,63)$.

Com base nos índices estatísticos mostrados na Tabela 4, é possível inferir-se que ambos os modelos tiveram melhor desempenho para a região da Torre Borborema em março e para a localidade da Torre Agreste em setembro. Para a localidade da Torre Sertão, o WRF mostrou-se melhor em março, ao passo que em setembro os índices estatísticos apontam o BRAMS como o melhor. Portanto, os resultados obtidos mostram que não há um modelo único que seja melhor em todos os casos aqui analisados.

\section{Conclusões}

Neste trabalhou avaliou-se o desempenho dos modelos BRAMS e WRF em identificar áreas favoráveis à geração de energia eólica no estado da Paraíba. Os resultados obtidos nos dois experimentos realizados, sazonal (BRAMS) e mensal (BRAMS e WRF), sugerem que os modelos são capazes de representar o comportamento do vento em média de forma satisfatória.

$\mathrm{Na}$ análise sazonal, o BRAMS conseguiu apontar que os períodos de ventos menos e mais intensos sobre a Paraíba ocorrem, respectivamente, durante o primeiro semestre (verão e outono) e o segundo semestre (inverno e primavera), sendo a primavera a estação que apresenta, em média, os valores de velocidade mais elevados. Os resultados das simulações sugerem ainda que o vento no interior do estado, em especial na região da Borborema, tende a ser mais intenso que nas demais regiões, tanto no primeiro quanto no segundo semestre.

Com relação aos cenários para os meses de março e setembro, os resultados gerados revelam a coerência dos modelos BRAMS e WRF em termos de intensificação/desintensificação dos ventos de acordo com a influência exercida pelos fenômenos meteorológicos atuantes em cada mês. No entanto, os modelos apresentaram dificuldades em precisar a magnitude do vento nas áreas analisadas.

Tabela 4 - Índices estatísticos obtidos para as séries de dados observados e simulados para março e setembro de 2010.

\begin{tabular}{|c|c|c|c|c|c|c|c|c|}
\hline \multirow{3}{*}{$\begin{array}{l}\text { Torres anemométricas/ } \\
\text { Mês analisado } \\
\text { Março } 2010\end{array}$} & \multicolumn{8}{|c|}{ Índices estatísticos } \\
\hline & \multicolumn{4}{|c|}{ BRAMS-OBS } & \multicolumn{4}{|c|}{ WRF-OBS } \\
\hline & Bias & $E A$ & $E Q M$ & $r$ & Bias & $E A$ & $E Q M$ & $r$ \\
\hline Torre Agreste & $-2,24$ & 2,26 & 2,40 & 0,80 & $-1,40$ & 1,51 & 1,70 & 0,73 \\
\hline Torre Borborema & $-0,31$ & 0,65 & 0,88 & 0,73 & 0,53 & 0,98 & 1,18 & 0,63 \\
\hline Torre Sertão & $-0,84$ & 1,02 & 1,27 & 0,80 & $-0,59$ & 1,01 & 1,22 & 0,74 \\
\hline Setembro 2010 & Bias & $E A$ & $E Q M$ & $r$ & Bias & $E A$ & $E Q M$ & $r$ \\
\hline Torre Agreste & 0,69 & 0,86 & 1,09 & 0,80 & $-0,33$ & 0,65 & 0,79 & 0,80 \\
\hline Torre Borborema & 1,47 & 1,47 & 1,63 & 0,77 & 1,81 & 1,81 & 1,92 & 0,81 \\
\hline Torre Sertão & 1,49 & 1,53 & 1,75 & 0,83 & 1,66 & 1,66 & 1,89 & 0,79 \\
\hline
\end{tabular}


Para minimizar as diferenças entre os dados simulados e observados, e como sugestão para trabalhos futuros, seria interessante a realização de novos experimentos utilizando um conjunto de parametrizações físicas iguais para ambos os modelos, ou mais próximas possíveis, bem como um refinamento de grade. Sugere-se também investigar questões relacionadas às atualizações das informações de cobertura do solo e mapa de vegetação nos modelos, uma vez que estes parâmetros exercem influência direta na reprodução do vento.

Contudo, tanto o BRAMS como WRF mostraram-se eficazes no levantamento de locais que apresentam condições de vento favoráveis à geração de energia eólica, podendo, portanto, serem utilizados como ferramenta inicial na investigação e direcionamento de sítios para exploração dos recursos eólicos.

\section{Agradecimentos}

Os autores agradecem a Coordenação de Aperfeiçoamento de Pessoal de Nível Superior (CAPES), pelo suporte financeiro e a Universidade Federal de Campina Grande.

\section{Referências}

AMARANTE, O.C.A.; BROWER, M.; ZACK, J.; SÁ, A.L. Atlas do Potencial Eólico Brasileiro. Brasília: e-dea Techologies, 2001.

ANEEL. Banco de Informações de Geração: BIG Capacidade de Geração do Brasil, 2017. Disponível em: http://www2.aneel.gov.br/aplicacoes/capacidadebrasil/Ger acaoTipoFase.asp. Acesso: 07 dez. 2017.

ANEEL. Banco de Informações de Geração: BIG Capacidade Instalada por Estado, 2018. Disponível em: http://www2.aneel.gov.br/aplicacoes/resumoestadual/resu moestadual.cfm. Acesso: 28 fev. 2018.

BURTON, T.; SHARPE, D.; JENKINS, N.; BOSSANYI, E. Handbook of wind energy. John Wiley \& Sons, p. 617, 2001.

CARVALHO, D.; ROCHA, A.; GÓMEZ-GESTEIRA, M.; SANTOS, C. A sensitivity study of the WRF model in wind simulation for an area of high wind energy. Environmental Modelling \& Software, v. 33, p. 23-34, 2012.

CHEN, F.; COTTON, W.R. A one-dimension simulation of the stratocumulus capped mixed layer. Boundary- Layer Meteorology, v. 25, p. 289-321, 1983.

CLIMANÁLISE. Boletim de Monitoramento e Análise Climática, v. 25, n. 3, 2010a. Disponível em: http://www.cptec.inpe.br/products/climanalise. Acesso em 11 mar 2018.

CLIMANÁLISE: Boletim de Monitoramento e Análise Climática, v. 25, n. $9,2010 \mathrm{~b}$. Disponível em: http://www.cptec.inpe.br/products/climanalise. Acesso em 11 mar 2018.

CUSTÓDIO, R.S. Energia eólica para produção de energia elétrica. Rio de janeiro, 2007.

CUNHA, E.B.A.C.; LEAL JUNIOR, J.B.V.; ALMEIDA, G.P. Sensibilidade do modelo RAMS à parametrização de turbulência na simulação de vento em região serrana. In: $\mathbf{X V}$
Congresso Brasileiro de Meteorologia, 2008, São Paulo. Anais Eletrônicos. Rio de Janeiro: SBMET, 2008.

DE MARIA, P.H.S. Modelagem numérica em alta resolução para previsão de geração de energia eólica no Ceará. 123f. Dissertação (Mestrado em Ciências Físicas Aplicadas) - Universidade Estadual do Ceará, 2007.

DEVORE, J.L. Probabilidade e estatística para engenharia e ciência. São Paulo: Thomson Pioneira, 706 p., 2006.

DOYLE, J.D.; SHAPIRO, M.A. Flow response to largescale topography: The greenland tip jet. Tellus, v. 51a, p. 728-748. 1999.

FEB: Força Eólica do Brasil, 2017. Disponível em: http://www.neoenergia.com/Pages/LINHAS $\% 20$ DE $\% 20 \mathrm{~N}$ EG\%C3\%93CIOS/For\%C3\%A7a\%20E\%C3\%B3lica\%20 do\%20Brasil.aspx. Acesso em 01 mar 2018.

FLOORS, R.; VINCENT, C.L.; GRYNING, S.E.; PEÑA, A.; BATCHVAROVA, E. The wind profile in the coastal boundary layer: Wind lidar measurements and numerical modelling. Bound-Lay Meteorol., v. 147, n. 3, p. 469-491, 2013.

FREITAS, S.R.; LONGO, K.M.; SILVA DIAS, M.; SILVA DIAS, P.; CHATFIELD, R.; et al. Monitoring the transport of biomass burning emissions in South America. Environmental Fluid Mechanics, v. 5, n. 1-2, p. 135-167, 2005.

FREITAS, S.R.; LONGO, K.M.; SILVA DIAS, M.A.F.; CHATFIELD, R.; et al. The Coupled Aerosol and Tracer Transport model to the Brazilian developments on the Regional Atmospheric Modeling System (CATT-BRAMS) - Part 1: Model description and evaluation, Atmos. Chem. Phys., v. 9, p. 2843-2861, 2009.

FREITAS, S.R.; PANETTA, J.; LONGO, K.M.; RODRIGUES, L.F.; MOREIRA, D.S.; et al. The Brazilian developments on the Regional Atmospheric Modeling System (BRAMS 5.2): an integrated environmental model tuned for tropical areas. Geosci. Model Dev. Discuss., v. 130, p. 1-55, 2016.

GONÇALVES, A.R. Refinamento estatístico das previsões de vento do modelo ETA aplicado ao setor eólio-elétrico do nordeste brasileiro. 151p. Dissertação (Mestrado em Meteorologia) - Instituto Nacional de Pesquisas Espaciais, 2011.

GRELL, G.A.; DEVENYI, D. A generalized approach to parameterizing convection combining ensemble and data assimilation techniques. Geophysical Research Letters, v. 29, n. 14, p. 1693, 2002.

HONG, S.Y.; NOH, Y.; DUDHIA, J. A new vertical diffusion package with an explicit treatment of entrainment processes. Mon. Wea. Rev., v. 134, p. 2318-234, 2006.

HU, X.M.; DOUGHTY, D.C.; SANCHEZ, K.J.; JOSEPH, E.; FUENTES, J.D. Ozone variability in the atmospheric boundary layer in Maryland and its implications for vertical transport model. Atmospheric Environment, v. 46, p. 354-364, 2012.

HU, X.M.; KLEIN, P.M.; XUE, M. Evaluation of the updated YSU planetary boundary layer scheme within WRF for wind resource and air quality assessments. J. Geoph. Res., v. 118, p. 10.490-10.505, 2013.

JIMÉNEZ, P.A.; DUDHIA, J.; GONZÁLEZ-ROUCO, J.F.; NAVARRO, J.; MONTÁVEZ, J.P.; GARCÍA-BUSTAMANTE, E. A Revised Scheme for the WRF Surface Layer Formulation. Monthly Weather Review. v. 140, n. 3, p. $898-918,2012$. 
KAYANO, M.T.; ANDREOLI, R.V. Clima da região Nordeste do Brasil. In: Iracema F.A. Cavalcanti et al. (orgs). Tempo e Clima no Brasil, São Paulo: Ofícina dos Textos, p. 213233, 2009.

KO, D.H.; JEONG, S.T.; KIM, Y.C. Assessment of wind energy for small-scale wind power in Chuuk State, Micronesia. Renewable and Sustainable Energy Reviews, v. 52, p. 613622, 2015.

LAYTON, J. Como funciona a energia eólica. 2009. Disponível em:

http://www.fiec.org.br/artigos/energia/energia_eolica.htm. Acesso em: 08 jan. 2013.

LIMA, F.J.L. Avaliação do potencial eólico no Estado da Paraíba: um estudo observacional e numérico. 80f. Dissertação (Mestrado em Meteorologia) - Universidade Federal de Campina Grande, 2011.

LIMA, F.J.L.; CAVALCANTI, E.P.; SOUZA, E.P.; SILVA, E.M. Evaluation of the Wind Power in the State of Paraíba Using the Mesoscale Atmospheric Model Brazilian Developments on the Regional Atmospheric Modelling System. ISRN Renewable Energy, v. 2012, p. 16, 2012.

LIN, Y.L.; FARLEY, R.D.; ORVILLE, H.D. Bulk parameterization of the snow field in a cloud model. J. Climate Appl. Meteor., v. 22, p. 1065-1092, 1983.

LONGO, K.M.; FREITAS, S.R.; PIRRE, M.; MARÉCAL, V.; RODRIGUES, L.F.; et al. The chemistry CATT BRAMS model (CCATT-BRAMS 4.5): a regional atmospheric model system for integrated air quality and weather forecasting and research. Geoscientific Model Development, v. 6, p. 1389-1405, 2013.

MARCHI, A.C. Estudo do vento para o Estado de Alagoas utilizando o modelo regional WRF: testes de parametrizações da camada limite planetária. 67f. TCC (Bacharelado em Meteorologia) - Universidade Federal de Alagoas, 2011.

MARIANO NETO, B. Geografia: Textos, Contextos e Pretextos para o Planejamento Ambiental. $1^{\text {a }}$ ed. - Guarabira: Gráfica São Paulo, 2003.

MATHEW, S.A.; MARIAPPAN, V.E.N. Wind Resource Land Mapping using ArcGIS, WAsP and Multi Criteria Decision Analysis (MCDA). Energy Procedia, v. 52, p. 666-675, 2014.

MELLOR, G.; YAMADA, T. Development of a turbulence closure model for use in geophysical fluid problems. Reviews of Geophysics and Space Physics, v. 20, p. 851-857, 1982.

MLAWER, E.J.; TAUBMAN, S.J.; BROWN, P.D.; IACONO, M.J.; CLOUGH, S.A. Radiative transfer for inhomogeneous atmospheres: RRTM, a validated correlated-k model for the longwave, J. Geophys. Res., v. 102(D14), p. 16663-16682, 1997.

MME (Brasil): Boletim de Energia Eólica no Brasil e Mundo Base 2016. Brasília, 2017. Ministério de Minas e Energia MME. Disponível em: http://www.mme.gov.br/documents/10584/3580498/15+-+Energia+E\%C3\%B3lica+-+B rasil+e+Mundo+-+ano+ref.+2016+\%28PDF\%29+-+NOV $\mathrm{O} / \mathrm{f} 63 \mathrm{a} 15 \mathrm{ea}-9 \mathrm{~d} 2 \mathrm{c}-4 \mathrm{~d} 27-9400-5 \mathrm{~d} 7 \mathrm{c} 3 \mathrm{fd} 97 \mathrm{~b} 22$ ?version $=1.4$. Acesso: 28 fev 2018.

NEGRI, R.G.; MACHADO, L.A.T.; FREITAS, S.R. Análise da convecção resolvida explicitamente pelo modelo BRAMS a partir da comparação com radiâncias de satélites. Rev. bras. Meteorol., v. 30, n. 3, p. 327-339, 2015.
OLIVEIRA, S.S. Análise do potencial eólico do estado da Paraíba utilizando modelos de mesoescala $127 \mathrm{f}$. Tese (Doutorado em Meteorologia) - Universidade Federal de Campina Grande, 2013.

OLIVEIRA, S.S.; SOUZA, E.P. Análise de Modelos de Mesoescala para Caracterização do Potencial Eólico do Estado da Paraíba. Revista Brasileira de Meteorologia, v. 32, n. 2, p. 277-291, 2017.

PIELKE, R.A.; COTTON, W.R.; WALKO, R.L.; TREMBACK, C.J.; LYONS, W.A.; et al. A comprehensive meteorological modeling system - RAMS. Meteorological and Atmospheric Physical, v. 49, p. 69-91, 1992.

POWERS, J.G.; KLEMP, J.B.; SKAMAROCK, W.C.; DAVIS, C.A.; DUDHIA, J.; et al. The Weather Research and Forecasting Model: Overview, System Efforts, and Future Directions. Bulletin of the American Meteorological Society, v. 98, n. 8, p. 1717-1737, 2017.

RAMOS, D.N.S.; LYRA, R.F.F.; SILVA JÚNIOR, R.S. Previsão do vento utilizando o modelo atmosférico WRF para o estado de Alagoas. Revista Brasileira de Meteorologia, v. 28, n. 2 , p. $163-172,2013$.

RAO, V.B.; MOSCATI, M.C.L.; FRANCHITO, S.H. Seasonal and interannual variations of rainfall over Eastern Northeast Brazil. Journal of Climate, v. 6, n. 9, p. 1754-1763, 1993.

RODRIGUEZ, J.L. Atlas Escolar da Paraíba. $3^{\text {a }}$ ed., João Pessoa: Editora Grafset, 2002.

RÜNCOS, F.; CARLSON, R.; KUO-PENG, P.; VOLTOLINI, H.; BATISTELA, N.J. Geração de Energia Eólica Tecnologias Atuais e Futuras. Revista Eletricidade Moderna, Brasil, v. 1, Mar. 2005.

SÁ, S. Energia limpa: Paraíba terá três Parques Eólicos até 2017. Fiep - Campina Grande/PB. Disponível em: http://www.fiepb.com.br/noticias/2016/08/19/energia_limp a paraiba tera tres parques_eolicos_ate 2017. Acesso em 08 dez. 2016.

SANSIGOLO, C.A. Distribuições de Probabilidade de Velocidade e Potência do Vento. Revista Brasileira de Meteorologia, v. 20, n. 2, p. 207-214, 2005.

SANTOS, M.; SANTIAGO, G.; GONZÁLEZ, M. Medição de Desempenho na Etapa de Prospecção de Parques Eólicos: O Que Medir? In: Brazil Windpower Conference, Rio de Janeiro-RJ, 2015. Disponível em: http://www2.ctee.com.br/brazilwindpower/2015/papers/ George_Santiago.pdf. Acesso em: 01 out. 2016.

SAUER, I.L.; QUEIROZ, M.S.; MIRAGAYA, J.C.G.; MASCARENHAS, R.C.; JÚNIOR, A.R.Q. Energias Renováveis: Ações e Perspectivas na Petrobras. Análise e Dados. Salvador, Bahia. v. 16, n. 01, p. 9-22. 2006.

SILVA, C.D.; SERAPHIM, O.J.; TEIXEIRA, N.M. Potencial eólico para bombeamento de água na fazenda Lageado. In: ENCONTRO DE ENERGIA NO MEIO RURAL 3, Campinas, 2003. Disponível em: http://www.proceedings.scielo.br/scielo.php?pid=MSC0000000022000 $000200032 \&$ script $=$ sci_arttext. Acesso em: 03 out. 2016.

SILVA, G.R. Características de Vento da Região Nordeste. $141 \mathrm{f}$. Dissertação (Mestrado em Engenharia Mecânica) Universidade Federal de Pernambuco, 2003.

SILVA, F. B. Análise dos efeitos combinados da ilha de calor e da poluição do ar urbanas. $266 \mathrm{p}$. Tese (Doutorado em Meteorologia) - Instituto Nacional de Pesquisas Espaciais, 2016. 
SILVA, N.F.; ROSA, L.P.; ARAÚJO, M.R. The utilization of Wind energy in the Brazilian electric sector's expansion. Renew. Sust. Energ. Rev., v. 9, p. 289-309, 2005.

SILVA, T.L.V. Análise da sensibilidade da parametrização de microfísica e cúmulos do modelo WRF: Estudo de caso dos dias 15 e 16 de maio de 2009 em Alagoas. TCC (Meteorologia) - Universidade Federal de Alagoas, Maceió, 2009.

SILVA, T.L.V.; OLIVEIRA, S.S.; STUDZINSKI, C. Estimativa do Potencial Eólico utilizando modelos de mesoescala Parte 1: Magnitude do vento. In: XVII Congresso Brasileiro de Meteorologia, Gramado, Rio Grande do Sul, 23-28 Setembro, 2012. Anais Eletrônicos. Gramado-RS, 2012.

SHIN, H.H.; HONG, S.Y. Intercomparison of planetary boundary-layer parametrizations in the WRF model for a single day from CASES-99. Bound-Lay Meteorol., v. 139, n. 2, p. 261-281, 2011.

SKAMAROCK, W.C.; KLEMP, J.B.; DUDHIA, J.; GILL, D.O.; BARKER, D.; et al. NCAR Technical Note: A description of the Advanced Research WRF version 3. 113 p. 2008.

SOUZA, E.P. Estudos teóricos e numéricos da relação entre convecção e superfície heterogêneas na região Amazônica. 121 f. Tese (Doutorado em Meteorologia) - Universidade de São Paulo, 1999.
VALENÇA, D.A.A. Proposição de uma metodologia para a avaliação do aproveitamento da energia eólica em ambiente urbano. 130f. Dissertação (Mestrado em Engenharia Mecânica) - Universidade Federal de Pernambuco, 2010.

WALKO, R.L.; COTTON, W.R.; MEYERS, M.P.; HARRINGTON, J.Y. New RAMS cloud microphysics parameterization part I: The single-moment scheme. Atmospheric Research, v. 38, n. 14, p. 29-62, 1995.

WANG, C.; HU, J.; FENG, S.; JIN, S.; ZHANG, F.; LIU, C. Comparing different boundary layer schemes of WRF by simulation the low-level wind over complex terrain. In: 2nd International Conference on Artificial Inteligence, Management Science and Electronic Commerce (AIMSEC), Zhengzhou, China. 2011.

WANG, Z.; SHEN, C.; LIU, F. A conditional model of wind power forecast errors and its application in scenario generation. Applied Energy. v. 212, p. 771-785, 2018.

WEBER, R.L.; BUCKNER, M.; WEBER, J. Statistical Performance of several mesoscale atmospheric dispersion models. Journal of Applied Meteorology, v. 21, n. 11, p. 1633$1644,1982$.

This is an Open Access article distributed under the terms of the Creative Commons Attribution Non-Commercial License which permits unrestricted non-commercial use, distribution, and reproduction in any medium provided the original work is properly cited. 